\title{
Urbanizaciones cerradas en el área sur de la ciudad de Santiago, 2010-2019
}

- Recepción: 31 de marzo de 2020 - Evaluación: 7 de mayo de 2021 - Aprobación: 10 de junio de 2021

Resumen: La literatura especializada ha caracterizado, dentro de las dimensiones fundamentales de la ciudad neoliberal, a la urbanización cerrada. De esa manera, conforma parte del paisaje de las distintas ciudades latinoamericanas. La edificación cerrada continúa proliferando y diversificándose en sus formas, ubicándose en distintos territorios donde existan condiciones para su reproducción. Este estudio tuvo como objetivo analizar las urbanizaciones cerradas en las comunas de Puente Alto, La Florida, San Bernardo, Maipú, Peñaflor, Padre Hurtado y Talagante, ubicadas al sur de la ciudad de Santiago de Chile. La metodología se basó en información proveniente de permisos de edificación, el portal inmobiliario Toctoc e imágenes satelitales integradas a un software de sIG. A partir de lo anterior, se examinaron las características de este tipo de complejos con el fin de evidenciar su comportamiento espacial. Los resultados generales establecen una proliferación tanto en las comunas que son parte del límite urbano consolidado como en las que se encuentran fuera, así como una gama de tipologías orientadas a diversos estratos sociales, desde proyectos sociales hasta otros de lujo. Pese a ser parte de la actual configuración territorial de la zona de estudio, las urbanizaciones cerradas presentan diferencias entre ellas y respecto del resto de construcciones aledañas, por lo que perpetúan procesos de fragmentación espacial.

Palabras claves: crecimiento urbano, fragmentación urbana, neoliberalismo, urbanización cerrada.

Para citar: Navarro,J.J.(2021). Urbanizaciones cerradas en elárea sur de la ciudad de Santiago, 2010-2019. Perspectiva Geográfica, 26(2), 132-150. https://doi.org/10.19053/01233769.11092. 


\title{
Gated communities in the southern area of the city of Santiago, 2010-2019
}

\begin{abstract}
The specialized literature has characterized closed urbanization as one of the fundamental dimensions of the neoliberal city. Thus, it is part of the landscape of different Latin American cities. Closed construction continues to proliferate and diversify in its forms, being located in different territories where conditions for its reproduction exist. The objective of this study was to analyze gated communities in the municipalities of Puente Alto, La Florida, San Bernardo, Maipú, Peñaflor, Padre Hurtado and Talagante, located south of the city of Santiago de Chile. The methodology was based on information obtained from building permits, the real estate portal Toctoc and satellite images integrated with GIS software. Based on the above, the characteristics of this type of complexes were examined in order to demonstrate their spatial behavior. The general results establish a proliferation both in the communes that are part of the consolidated urban boundary and in those that are outside, as well as a range of typologies oriented to different social strata, from social projects to luxury ones. Despite being part of the current territorial configuration of the study area, the gated communities present differences among themselves and with respect to the rest of the surrounding constructions, which perpetuate processes of spatial fragmentation.
\end{abstract}

Keywords: urban growth, urban fragmentation, neoliberalism, gated communities.

\section{Urbanizações fechadas na área sul da cidade de Santiago, 2010-2019}

Resumo: A literatura especializada tem caracterizado, dentro das dimensões fundamentais da cidade neoliberal, à urbanização fechada. Dessa forma, faz parte da paisagem das diferentes cidades latino-americanas. A edificação fechada continua a proliferar e diversificarse nas suas formas, localizando-se em diferentes territórios onde existam condições para a sua reprodução. Este estudo teve como objetivo analisar as urbanizações fechadas nas comunas de Puente Alto, La Florida, San Bernardo, Maipú, Peñaflor, Padre Hurtado e Talagante, localizadas ao sul da cidade de Santiago do Chile. A metodologia baseou-se em informações provenientes de licenças de edificação, o portal imobiliário Toctoc e imagens de satélite integradas a um software de SIG. Com base no que precede, as características deste tipo de complexos foram examinadas a fim de evidenciar o seu comportamento espacial. Os resultados gerais estabelecem uma proliferação tanto nas comunas que são parte do limite urbano consolidado como nas que se encontram fora, bem como uma gama de tipologias orientadas a diversos estratos sociais, desde projetos sociais até outros de luxo. Apesar de fazerem parte da atual configuração territorial da zona de estudo, as urbanizações fechadas apresentam diferenças entre si e em relação às outras construções circundantes, pelo que perpetuam processos de fragmentação espacial.

Palavras-chave: crescimento urbano, fragmentação urbana, neoliberalismo, urbanização fechada. 


\section{Introducción}

Dentro de las características y atributos de la ciudad latinoamericana global, se encuentran la fragmentación del espacio urbano, su segregación residencial en grupos de acuerdo con ingresos y la proliferación de objetos urbanos que mantienen una morfología de cierre, ruptura y quiebres (De Mattos, 2002; Janoschka, 2002). Entonces, el medio urbano contemporáneo se encuentra atravesado por una pérdida profunda del espacio público y bajo una primacía de lo privado.

El modelo neoliberal de gobernanza urbana tiene su expresión material en la ciudad de Santiago de Chile, que no se encuentra ajena a las profundas desigualdades de los espacios urbanos a nivel latinoamericano. Santiago también ha presentado, desde finales de los noventa, una proliferación de nuevos complejos cerrados, ya sean de gran envergadura o de menor tamaño (Hidalgo et al., 2007). Al mismo tiempo, esta morfología se ha presentado tanto en el sector oriente de la ciudad, en donde se encuentran los grupos de mayores ingresos, o de manera dispersa, donde se encuentran las condiciones de presencia de suelo e infraestructura que le permiten existir y reproducirse.

Este estudio tuvo como objetivo analizar las urbanizaciones cerradas en algunas comunas ubicadas al sur de la ciudad de Santiago de Chile desde la construcción y la oferta de vivienda entre los años 2010 a 2019 para establecer una espacialidad del área de estudio, entendiendo que la espacialidad es el producto social de las acciones y las relaciones sociales materialmente constituidas (Montañez, 1999). Para lograr esto se trabajó con información proveniente del Instituto Nacional de Estadística y de un portal inmobiliario especializado. El sentido de una investigación de esta naturaleza corresponde a una materialización de discusiones a nivel latinoamericano sobre las urbanizaciones cerradas y su materialización en una zona de Santiago de Chile no tan documentada, donde existen las condiciones para su proliferación.
Este artículo se presenta de la siguiente manera: en primer lugar, un marco teórico acerca de las urbanizaciones cerradas; posteriormente, los métodos y las técnicas con las que se trabajó; en el apartado de los resultados se presentan los elementos cuantitativos obtenidos de las distintas fuentes de información, a la vez que algunos atributos de algunos de los proyectos con cierre y una tipología emergente con base en autores que han trabajado la temática.

\section{Marco teórico}

La literatura, en general, ha considerado los efectos globalizadores, en conjunto con las políticas neoliberales, como elementos fundamentales en la configuración territorial de los espacios urbanos de la región (De Mattos, 2002; Janoschka; 2002). En ese sentido, la privatización de lo urbanamente público posee su expresión en una política orientada a empresas privadas y agentes inmobiliarios, todo lo anterior con cierta complicidad de parte de Gobiernos metropolitanos y locales (López-Morales et al., 2012).

Por otra parte, dos conceptos esenciales explican la compleja configuración espacial de la ciudad latinoamericana en conjunto con sus profundas contradicciones internas: fragmentación y segregación (Janoschka, 2002; Sabatini el al., 2001; De Mattos, 2002). En efecto, la ciudad latinoamericana se encuentra a travesada por desigualdades internas que profundizan una separación estructural entre un polo de alta renta y una periferia marginalizada (Janoschka, 2002). La segregación corresponde a una separación de grupos humanos principalmente por su nivel socioeconómico o sus características culturales, lo cual establece concentración de estos y exclusión social (Sabatini et al., 2001). Por otro lado, la fragmentación se materializa en quiebres de continuidad dentro del espacio urbano a partir de limitaciones en el movimiento y el acceso (Janoschka, 2002).

Las políticas de vivienda social tienen un impacto en la configuración de la segregación y la fragmentación 
al crear espacios de marginalización desde el Estado. Desde la dictadura militar, la periferia de la ciudad de Santiago fue receptora de vivienda social, tanto en lo que se refiere a relocalización de campamentos, desde una mirada de higiene social, como en los gobiernos democráticos transicionales con la política de producción en masa de vivienda (Tapia, 2011; Hidalgo, 2005). En algunos casos, como consecuencia radical de dichas visiones, se crearon guetos urbanos, verdaderos espacios de marginación social a partir de la llegada masiva de población sin un vínculo común claro, donde la ausencia estatal marcó, tras sus primeros años, nuevas lógicas de poder internas relacionadas con el narcotráfico. Junto con lo anterior, una modernización neoliberal amparada desde los conceptos de los Chicagos Boys (Vergara-Perucich, 2017), un grupo de civiles que participaron activamente en el cambio del modelo económico chileno, formados en la escuela homónima estadounidense, transformaron el espacio en la materialización de dicha ideología al convertirlo en un factor de capitalización inmobiliaria y proponer una expansión urbanizadora como hasta entonces no había existido.

En los últimos años, se produjo una desconcentración de los grupos de mayores ingresos hacia nuevas zonas de la ciudad en donde existe disponibilidad de suelo (Sabatini et al., 2017). De esa manera, la segregación ha tendido a cambiar su patrón tradicional, permitiendo la coexistencia en un mismo territorio de grupos sociales diversos.

Frente al fin del Estado benefactor y el comienzo de las políticas neoliberales subsidiarias, donde los privados se encuentran con libertad en la construcción de ciudad, aparece nuevas formas de hábitat y residencia. Los objetos amparados en una lógica comercializadora del territorio, como shoppings y distritos financieros, han sido acompañados por complejos de vivienda que se articulan desde el encierro y la seguridad. Es así como las urbanizaciones cerradas emergen dentro de este panorama general. Desde finales del siglo xx, urbanizaciones de elite alejadas de los centros urbanos aparecen relacionadas con los grupos de altos ingresos y la exclusividad (Janoschka, 2002; Borsdof, 2002).

La literatura acerca de las urbanizaciones cerradas posee dos grandes periodizaciones. La primera, de carácter fundante, evidencia su aparición desde los noventa en términos generales y establece cuáles son los elementos identitarios de este nuevo objeto urbano (Janoschka, 2002; Borsdof, 2002). La segunda se refiere a casos específicos a nivel de países y ciudades que corroboran, discuten o complementan dichas afirmaciones, como ocurre en Argentina (Arizaga, 2003; Carballo, 2002; Thuillier, 2005), Chile (Hidalgo, 2004; Hidalgo et al., 2007), México (Cabrales \& Canosa, 2001; Enríquez, 2007; Contreras et al., 2018) o Brasil (De Lima \& Ribeiro, 2002; Souza, 2008).

El problema con las urbanizaciones cerradas es que no poseen una definición única y común aplicable a todas las experiencias de las ciudades y los países latinoamericanos. Roitman (2016) establece que depende de las condiciones particulares de cada región y sus contextos. Edward Soja (2008) introduce las urbanizaciones cerradas con el concepto del archipiélago carcelario. Las ciudades de las posmetrópolis encuentran en su ideología y comportamiento espacial una obsesión con la seguridad que se traduce en encierro, pérdida del espacio público, control policial y compra de armamento para la seguridad privada. La ciudad fortificada tiene su origen en urbanizaciones con acceso restringido y perímetros marcados cuya finalidad es brindar protección del exterior.

Sobre las características generales de las urbanizaciones cerradas, existe cierto consenso acerca de dos factores esenciales: los límites físicos y el control de acceso (Roitman, 2004; Hidalgo et al., 2007; Calleja, 2018; Pfannenstein et al., 2017). Roitman (2004) menciona que la dificultad de una definición común se encuentra en la gran cantidad de espacios que se mencionan como tal. Pese a dicha situación, las urbanizaciones cerradas pueden ser clasificadas a partir de la existencia de viviendas unifamiliares privadas, un 
espacio concebido desde su inicio como un lugar cerrado cuya infraestructura solo es beneficiosa para los residentes (Roitman, 2004; Calleja, 2018; Janoshka \& Glasze, 2003).

Algunas definiciones generales sobre los tipos de urbanizaciones cerradas conllevan principalmente una clasificación económica y de tamaño. Así, existen ciertas urbanizaciones orientadas a sectores con altos ingresos (Borsdorf, 2002; Cabrales, 2006; Pfannenstein et al., 2017), cuyos atributos y precios las convierten en bienes de lujo y establecen claras diferencias entre el "adentro" y el "afuera". Otras están orientadas a sectores arribistas o clases medias altas (Borsdorf, 2002; Pfannenstein et al., 2017), cuyo atributo principal es ofrecer un estatus social. Por contrapartida, hay urbanizaciones de interés social o subvencionadas en donde el cierre se justifica por seguridad e imitación de los anteriores (Hidalgo et al., 2007; Borsdorf, 2002; Pfannenstein et al., 2017; Roitman, 2016). Hidalgo (2004) establece que las urbanizaciones cerradas corresponden a proyectos de más de cien viviendas, con lo cual se diferencian formas de copropiedad. También existen microurbanizaciones o pequeños conjuntos (Pfannenstein et al., 2017).

Las urbanizaciones cerradas también tienen un papel colonizador en los espacios rurales cercanos a los centros urbanos consolidados (Cabrales, 2006). Las nuevas formas de habitar crean una ciudad dispersa, con discontinuidades y conexiones en red (Gómez, 2011). En el caso chileno, se han integrado a espacios rurales mediante la modificación de la planificación de los usos del suelo y la permisividad de la división de predios agrícolas (Hidalgo et al., 2007). De esta forma, su proliferación provoca una competencia y la posibilidad, de parte de los agentes inmobiliarios, de generar negocios con altas rentas.

Desde otra perspectiva, Roitman (2016) argumenta una diferenciación en torno una urbanización cerrada real, con características lujosas y un alto precio de adquisición que crea una diferenciación social y una fragmentación profunda. En contraposición, se presenta una urbanización cerrada falsa, la cual corresponde a los esfuerzos tanto de grupos vulnerables como del Estado y de los privados en la construcción de proyectos con cierre, además de cierta infraestructura que imita a las anteriores, inclusive en la utilización de estrategias de marketing y publicidad.

Otra manifestación de construcción de un espacio urbano amurallado corresponde a las denominadas "ciudades valladas". Dicho tipo específico de urbanización cerrada abarca proyectos de gran envergadura, construidos por etapas y ubicados en la periferia de la ciudad (Hidalgo et al., 2007). En Chile, se encuentran directamente relacionadas con las zonas de desarrollo urbano condicionado (ZODUC), que a partir de la planificación urbana regional crean infraestructura asociada. En su interior, presentan alta cantidad de servicios y equipamiento que les otorga cierto grado de autonomía en su entorno cercano. En Santiago, las ciudades valladas han sido identificadas como edificaciones que poseen entre quinientas y mil viviendas. Se ubican en comunas periféricas como Puente Alto, Peñalolén y Huechuraba. Su orientación social tiende hacia sectores medios altos y altos.

Entre las consecuencias de las urbanizaciones cerradas, se destacan la fragmentación del espacio asociado a ellas, la creación de verdaderas islas amuralladas y la diferenciación entre adentro y afuera de dichos complejos (Janoshka \& Glasze, 2003; Roitam; 2006; Cabrales, 2006). La pérdida del espacio público es considerada como la principal amenaza de estos proyectos, en la medida en que la exclusión social y el encierro se transforman en los imperativos de construcción de ciudad (Hidalgo et al., 2007; Roitman, 2003). Por otro lado, algunos estudios han planteado la posibilidad, en ciertos casos, de beneficios mediante infraestructura y mejoramientos que se emplazan en áreas de acceso público, fuera de las urbanizaciones, que tienden a matizar los juicios al respecto (Contreras et al., 2018; Pfannenstein et al., 2017).

En torno a la explicación del surgimiento de las urbanizaciones cerradas, una primera aproximación 
corresponde a la exclusión de grupos mediante el poder adquisitivo que poseen los sectores ricos de la sociedad (Borsdorf, 2002; Roitman, 2004). El aumento de los índices de criminalidad y la sensación de miedo generalizada son otros elementos que apoyan la necesidad de seguridad y encierro (Díaz \& Ortiz, 2014).

De manera más consensuada, el ejercicio político territorial es considerado como la principal causa de la aparición de las urbanizaciones cerradas. La gobernanza neoliberal del espacio presentó como atributos fundamentales la privatización del espacio público y una liberalización de los suelos, con lo cual se establece que es el mercado quien regula tanto la ciudad como el comportamiento de las personas (Borsdorf, 2002; Roitman, 2004; Hidalgo et al., 2007; Janoshka, 2002).

Otra postura plantea que el Estado, al ser incapaz de ofrecer ciertos servicios a los habitantes de la ciudad, ha hecho intencionadamente que estas necesidades sean satisfechas por parte de los privados. Entonces, los grupos familiares encontraron protección en las urbanizaciones cerradas (Pfannenstein et al., 2017). La fortificación es una consecuencia tanto de las modernizaciones neoliberales como de los intereses locales en propiciar un determinado urbanismo proempresarial.

En este estudio en particular, tomaremos como referencia las urbanizaciones cerradas como fenómenos transversales dentro de la ciudad latinoamericana, considerando las diversas diferencias entre sus manifestaciones y la persistencia del factor de exclusividad en su forma más radical y alejada de otros grupos sociales.

\section{Metodología}

El área de estudio correspondió a las comunas de Puente Alto, La Florida, San Bernardo, Maipú, Peñaflor, Padre Hurtado y Talagante de la Región Metropolitana de Santiago, como se presenta en la Figura 1. Estas comunas están ubicadas en la periferia del límite urbano consolidado y corresponden a espacios tradicionalmente rurales.
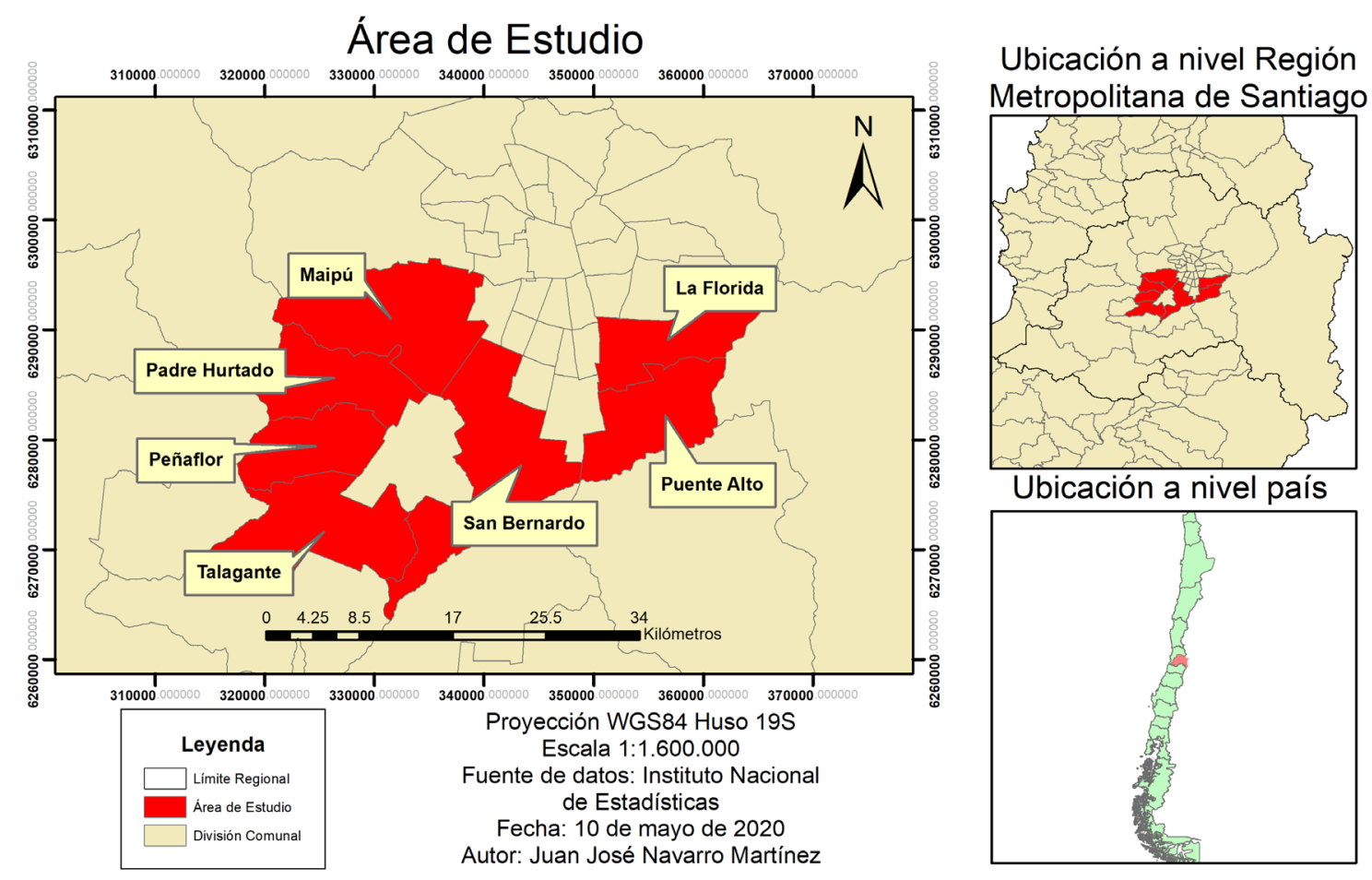

FIGURA 1. Área de estudio

FUENTE: elaboración propia a partir de base cartográfica, Censo de Población y Vivienda 2017 (Instituto Nacional de Estadísticas [INE], 2017). 
La fuente de información son los permisos de edificación entre los años 2010-2018 registrados en el Instituto Nacional de Estadísticas de Chile (2020), con los cuales fue posible localizar los proyectos que se encuentran en el área de estudio durante dicha temporalidad, que es la disponibilidad de datos a la hora de realizar el estudio. Estos permisos se trabajaron de manera georreferenciada y se integraron al software SIG ArcGIS.

Con los datos anteriores, solo es posible acceder a todo lo construido. Para definir cuáles de aquellas construcciones correspondían a urbanizaciones cerradas, se usaron como referencia las descripciones de la literatura revisada (Janoschka \& Glaze, 2003; Roitman, 2004; Hidalgo et al., 2007; Calleja, 2018; Pfannenstein et al., 2017), buscando encontrar portones de acceso, casetas de guardias y espacios interiores cercados, y se analizaron los permisos con imágenes satelitales de Google Earth. En los casos en que no fue posible encontrar algún atributo de discontinuidad del espacio público, no existieran imágenes o el proyecto aún no estuviera totalmente terminado, no fueron considerados como urbanizaciones cerradas.

Esta primera aproximación se fue complementado con la oferta presente en el portal inmobiliario Toctoc (IConstruye, 2020), desde donde se accedió a precios de vivienda, ubicación y características generales. Finalmente, se confeccionaron cartografias sintéticas acerca de la construcción de urbanizaciones cerradas.

Por otra parte, con la descripción de los proyectos y las características generales evidenciadas con el catastro construido se elaboraron tipologías de urbanizaciones cerradas para el área de estudio. El proceso metodológico se resume en los siguientes pasos:

1. Catastro de las urbanizaciones cerradas construidas a partir de las fuentes de información.

2. Análisis de las características de cada complejo: se trabajó principalmente desde tres perspectivas: a) precios de las viviendas, b) características internas de los complejos y c) publicidad.
3. Establecimiento de tipología: se hizo una revisión bibliográfica en torno a estudios de otros autores para evidenciar cuáles son los principales atributos que pueden definirlas y de qué manera realizar una discriminación aplicada al caso de estudio.

\section{Resultados}

En términos macro, previo a la temporalidad de este estudio, la ciudad de Santiago de Chile estuvo atravesada por dos grandes procesos en torno a la vivienda. El primero se desarrolló durante la dictadura militar de Augusto Pinochet Ugarte y se caracterizó por la relocalización de campamentos que se encontraban dentro del anillo urbano de la ciudad y en el sector oriente —zonas que mayoritariamente posee la población con más altos ingresos del país - hacia zonas periféricas de Santiago. Esta situación se acompañó de vivienda social, de una expansión del límite urbano y de una nueva legislación que planteó al suelo como un bien no escaso y permitió su trazabilidad en el mercado. El segundo proceso, ubicado temporalmente en la década de los noventa, partió de un profundo déficit de vivienda y significó la construcción masiva de viviendas sociales en espacios de la periferia de la ciudad, a la que vez que se ofrecía un incentivo privado mediante subsidios para clases medias.

La disponibilidad de superficie para urbanizar y los precios de suelo menores que los del centro y el oriente de la ciudad son los factores primordiales que explican la proliferación de proyectos inmobiliarios en las comunas estudiadas. Puente Alto, Maipú y La Florida lograron un crecimiento exponencial de acuerdo con los resultados que arrojan los censos de 1992 y 2002 (Instituto Nacional de Estadísticas) y se convirtieron en las comunas con mayor población del país. Lo anterior se explica a partir de las políticas de vivienda social y subsidiable en la década de los noventa, como mencionamos.

Los permisos de edificación nos permiten, en primera instancia, establecer zonas en torno al desarrollo 
inmobiliario según si corresponden a departamentos o viviendas unifamiliares. En la Figura 2 se presentan los permisos de edificación provenientes del Instituto Nacional Estadísticas en las comunas estudiadas. Del total de 442 permisos de edificación, 137 corresponden a departamentos y 305 a casas; en ese caso solo fueron tomadas las que poseen desde diez unidades en adelante.

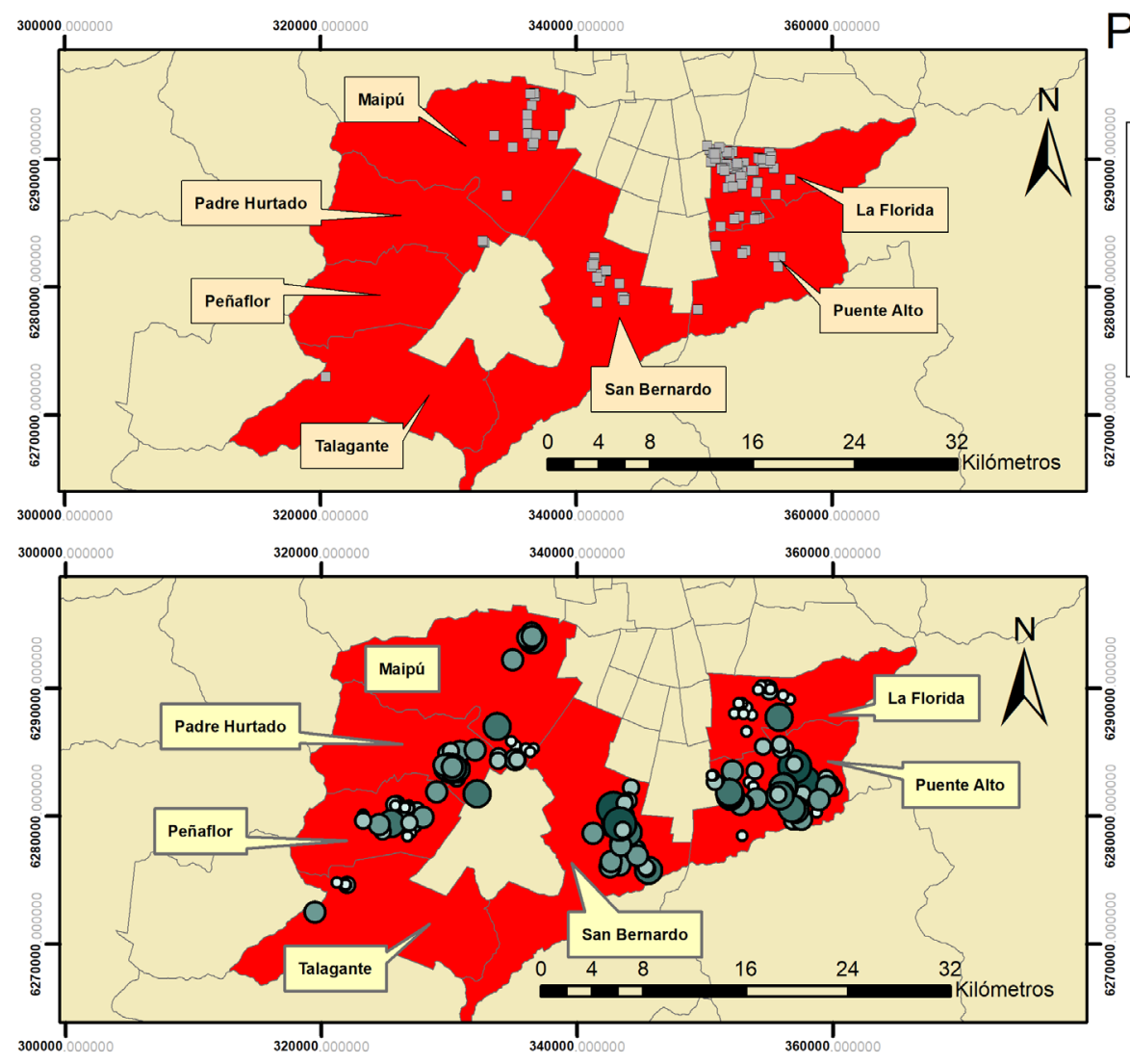

\section{Permisos de edificación área de estudio}

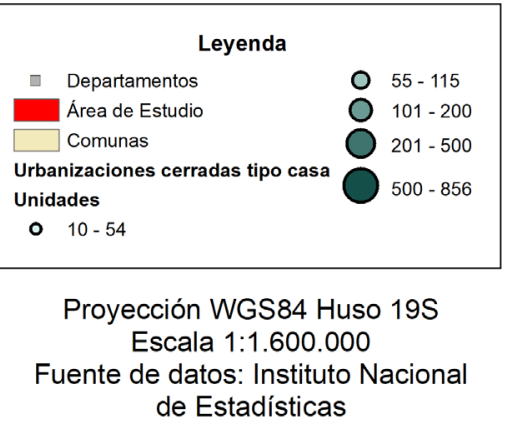

Fecha: 10 de mayo de 2020

Autor: Juan José Navarro Martínez

Ubicación Región Metropolitana

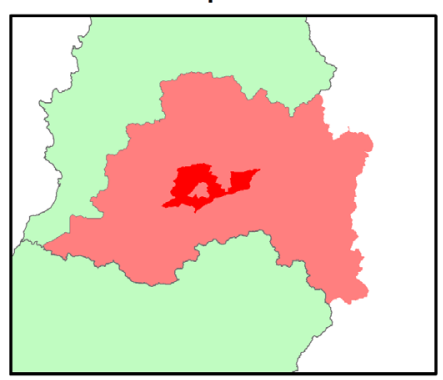

FIGURA 2. Permisos de edificación en el área de estudio

FUENTE: elaboración propia con base cartográfica, Censo de Población y Vivienda 2017 (INE, 2017) y permisos de edificación del Instituto Nacional de Estadística (INE, 2020).

De manera general, las zonas de desarrollo en altura tienden a presentarse en sitios específicos como la zona norte de la comuna de La Florida, cuya concentración de edificios de departamentos (91 en total) es mayor que en el resto de las comunas. Una situación similar ocurre en Maipú, donde existe un eje en el sector septentrional. San Bernardo posee desarrollo vertical en su centro, fenómeno que se repite en Puente Alto.

Referente a la construcción de vivienda y su distribución, corresponde a 81 en Puente Alto, 45 en Padre Hurtado, 27 en San Bernardo, 24 en Maipú, 21 en Peñaflor, 3 en La Florida y 3 en Talagante. De esta manera, existe una mayor proliferación de este tipo de construcción en tres ejes: Puente Alto, San Bernardo dirección sur y la continuidad entre Maipú, Padre Hurtado y Peñaflor. En estos casos, la explicación se encuentra relacionada con la presencia de suelo para urbanizar y la expansión del área urbana consolidada en términos generales, auspiciada en gran medida por la planificación local y regional que en las últimas décadas ha aumentado el suelo para urbanizar, además de que el Plan Regulador Metropolitano de Santiago establece a San Bernardo como una de las principales comunas con suelo disponible. Los planes reguladores comunales han generado zonificaciones relacionadas también con la expansión urbana. Por otro lado, los 
permisos por sobre las cien unidades de vivienda corresponden a 137. De este grupo, 9 sobre pasan las quinientas unidades y se ubican en Puente Alto, San Bernardo, Padre Hurtado y Peñaflor, lo que refleja un sentido de expansión urbana en estos espacios.

En el caso específico de las viviendas unifamiliares tipo casa, como se mencionó en el apartado de la metodología, con la ayuda de imágenes satelitales se discriminó si estas correspondían o no a urbanizaciones cerradas. Del total de 305 proyectos, 214 contenían algunos de los aspectos relacionados, como casetas de guardias y portones de acceso.

Esta descripción general nos permite establecer la forma en que el espacio urbano se expandió entre la temporalidad 2010-2018. En los primeros años se encuentra la mayor cantidad de viviendas unifamiliares, mientras que los departamentos despegan desde el 2014 en adelante. Esto puede ser explicado a partir de un avance de la oferta vertical hacia zonas alejadas del centro histórico, donde los departamentos existen, al mismo tiempo que se presentan ajustes de la regulación local que permiten construir en altura, como en el caso de La Florida.

Pasando a los resultados de la base de datos elaborada a partir de la oferta inmobiliaria encontrada en el portal Toctoc, corresponde a 152 en total y se presenta en la Figura 3. De aquellos, 75 son de tipo casa y 77 son departamentos, lo que nos da una noción de aproximación a que en el área de estudio se construye una cantidad similar de cada cual.

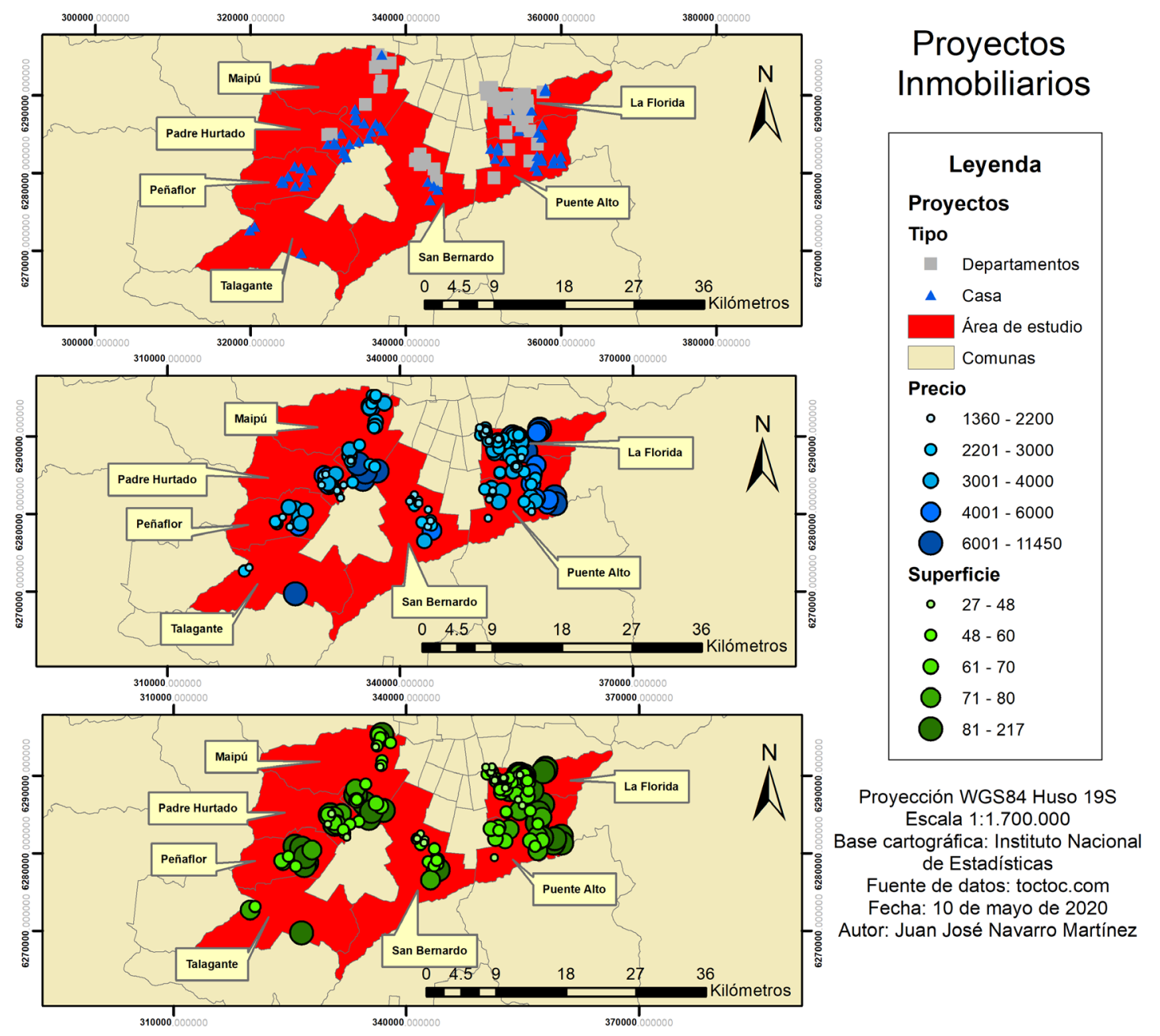

FIGURA 3. Proyectos inmobiliarios en área de estudio

FUENTE: elaboración propia con base cartográfica, Censo de Población y Vivienda 2017 (INE, 2017) y proyectos inmobiliarios de portal Toctoc (IConstruye, 2020). 
En términos de distribución espacial, 60 se encuentran en la comuna de La Florida, 24 en Puente Alto, 23 en Maipú, 16 en San Bernardo, 15 en Padre Hurtado, 11 en Peñaflor y 3 en Talagante. Estas magnitudes permiten corroborar la primera aproximación obtenida mediante los permisos de edificación que sitúan a La Florida y Puente Alto como las principales comunas donde se concentra la oferta inmobiliaria.

En lo que se refiere a la denominación de cada uno de los proyectos, se destaca que 39 de ellos poseen el nombre de "condominio", haciendo una directa alusión a su condición de entidad cerrada. "Condominio", en Chile, se refiere tanto a elementos de copropiedad como también al símil de las gated cities norteamericanas y hace referencia a un grupo de viviendas cerradas. Otros nombres que destacan se vinculan principalmente a su relación con el entorno, con conceptos como "parque", "valle" o "jardines".

Respecto a los precios de las viviendas, 85 proyectos se encuentran en el rango de 1.000 a 3.000 UF$^{2}, 36$ entre 3.000 a 4.000, 21 entre 4.000 y 6.000, y finalmente hay 10 por sobre las 6.000 UF. Su distribución en torno a los mayores precios tiende a ser la siguiente: por un lado, se concentran en la zona oriente de Puente Alto y La Florida y, por otra parte, en el sur de Maipú y una parte de Padre Hurtado.

De toda la oferta encontrada en el área de estudio, solo $32(21 \%)$ corresponden a vivienda subsidiable. Esta situación significa que las familias de clases bajas y medias pueden acceder a viviendas de hasta 2.200 UF (76.327 dólares). Para obtener dicha ayuda estatal, un grupo familiar debe tener un ahorro previo, dependiendo del subsidio en particular que quieren obtener, y pertenecer a ciertos tramos de acuerdo con la caracterización económica del Registro Social de

2 Una unidad de fomento (UF) corresponde a 34,37 dólares americanos.
Hogares $^{3}$ que establece la vulnerabilidad social de cada unidad.

El primero de estos subsidios corresponde a la denominación Ds19, que propone que las inmobiliarias ofrezcan viviendas accesibles a grupos vulnerables, con buena infraestructura y ubicación, ya que su criterio esencial es la integración social. En el área de estudio existen 8 proyectos orientados hacia este subsidio. El segundo caso corresponde al subsidio DS01, que permite adquirir una vivienda de hasta 2.200 UF y corresponde a 24 casos.

Respecto a las superficies, tienen una variación desde 27 a $217 \mathrm{~m}^{2}$. Las superficies más bajas corresponden principalmente a edificios de departamentos. Ocurre en variados casos que los proyectos presentan las características de departamentos de un solo dormitorio, por lo que en general los resultados terminan siendo bajos al considerar solo las superficies mínimas de cada uno. El grueso de los proyectos posee entre 48 a $70 \mathrm{~m}^{2}$.

La distribución de casos en relación con la superficie tiende a coincidir con el precio de las viviendas. De esa forma, existe una correlación entre ambas dimensiones: las viviendas de mayor tamaño y precio se encuentran en el oriente de Puente Alto y La Florida, y al sur de la comuna de Maipú.

La oferta inmobiliaria presente en el portal inmobiliario Toctoc describe los atributos propios de los distintos proyectos. Existen características que son compartidas por todos, dentro de las que se destacan, por sobre todas, las condiciones de cierre. Aparecen descripciones tales como cierre controlado, portones eléctricos, seguridad privada y vigilancia mediante circuito cerrado de televisión, entre otras. De esta forma, se presentan las cualidades de las urbanizaciones cerradas en torno a los límites físicos y la seguridad

3 El Registro Social de Hogares es la forma de caracterizar el nivel económico de los hogares en el país en torno a factores como los ingresos, el nivel educacional y la cantidad de habitantes. 
(Roitman, 2004; Hidalgo et al., 2007; Calleja, 2018; Pfannenstein et al., 2017).

Esta dimensión compartida en términos generales posee una diferenciación de acuerdo con los precios de las viviendas. Entre los proyectos subsidiables aparecen principalmente características de cierre tipo portones o conserjería. Sin embargo, a medida que los precios suben aparecen otros, como el cercado eléctrico, los perímetros demarcados y controlados, alarmas, portones automáticos de acceso a espacios interiores y domicilios. La seguridad sigue siendo un atributo fundamental, aunque se diferencia de acuerdo con el valor que tengan.

Si comparamos el equipamiento de los proyectos, sucede una situación similar: algunos proyectos subsidiables y con precios mayores presentan, dentro de sus áreas comunes, quinchos, áreas verdes o plazas, juegos infantiles, piscinas y estacionamientos para bicicletas. Obviamente existen variacion es dependiendo de si se toman los casos de departamentos o casas. Ahora, gimnasios, ciclovías o grandes parques interiores existen dentro de los atributos de los proyectos de mayor precio, orientados a sectores más acomodados. Inclusive en el proyecto Condominio Entre Cerros de Talagante se menciona su cercanía con clubes de golf y tenis.

Los proyectos con mayor precio hacen gala de su tamaño, como en Casa Quinta de Maipú: “¿quieres una piscina, una cancha de fútbol, una casa en el árbol o una huerta? En su inmenso jardín todo es posible: tener un patio así de grande te entrega la libertad de hacer lo que se te ocurra. El espacio no volverá a ser un problema" (IConstruye, 2020). Dicha situación también se configura desde de la producción social de naturaleza como una capacidad por parte de los grupos sociales de reproducir elementos naturales con fines paisajísticos, ornamentales, recreativos y de acumulación (Smith, 2008; Heynen, 2006). Sobre este último punto, tenemos el caso de Alto Macul en la comuna de La Florida, que menciona la presencia de $140 \mathrm{~m}^{2}$ de reserva ecológica.
Los proyectos que se encuentran en la lejanía de las zonas más urbanizadas de cada comuna explotan su ubicación con el propósito de presentar en su oferta un entorno natural. La naturaleza se vuelve un atributo de diferenciación social ya que, pese a que existe una presencia general de áreas verdes en cada proyecto, los de mayor precio son los que logran ostentar una mayor cantidad de superficie de este tipo. En ciertos casos, aparecen espacios con vegetación artificial de libre uso, ya que no están dentro de los perímetros cerrados, como ocurre en Ciudad del Sol, en Puente Alto, que posee un corredor central con equipamiento público, como juegos infantiles o infraestructura deportiva.

Laguna del Sol en Padre Hurtado y Laguna Cóndores en San Bernardo se salen de la norma en comparación con el resto de los proyectos, ya que en ambos casos su elemento de definición es la presencia de lagunas artificiales producidas por la empresa internacional Crystal Lagoons. Las lagunas tienen un fin estético, pero también permiten la realización de actividades deportivas durante todo el año. En su morfología, simulan playas o paisajes tropicales, como se muestra en la Figura 4. Este atributo claramente establece una reproducción de naturaleza con fines acumulativos, a la vez que el lujo y la exclusividad son fundamentales en su despliegue espacial.

\subsection{Hacia una tipología de las urbanizaciones cerradas}

Los aspectos encontrados en este caso de estudio permiten retomar algunas ideas abordadas en el apartado teórico de este trabajo. En ese sentido, es posible establecer, a partir de una discusión con otras investigaciones, dos tipos manifestaciones de las urbanizaciones cerradas en el área de estudio: la primera, de acuerdo con su tamaño, y la segunda depende de su orientación social y su precio. 


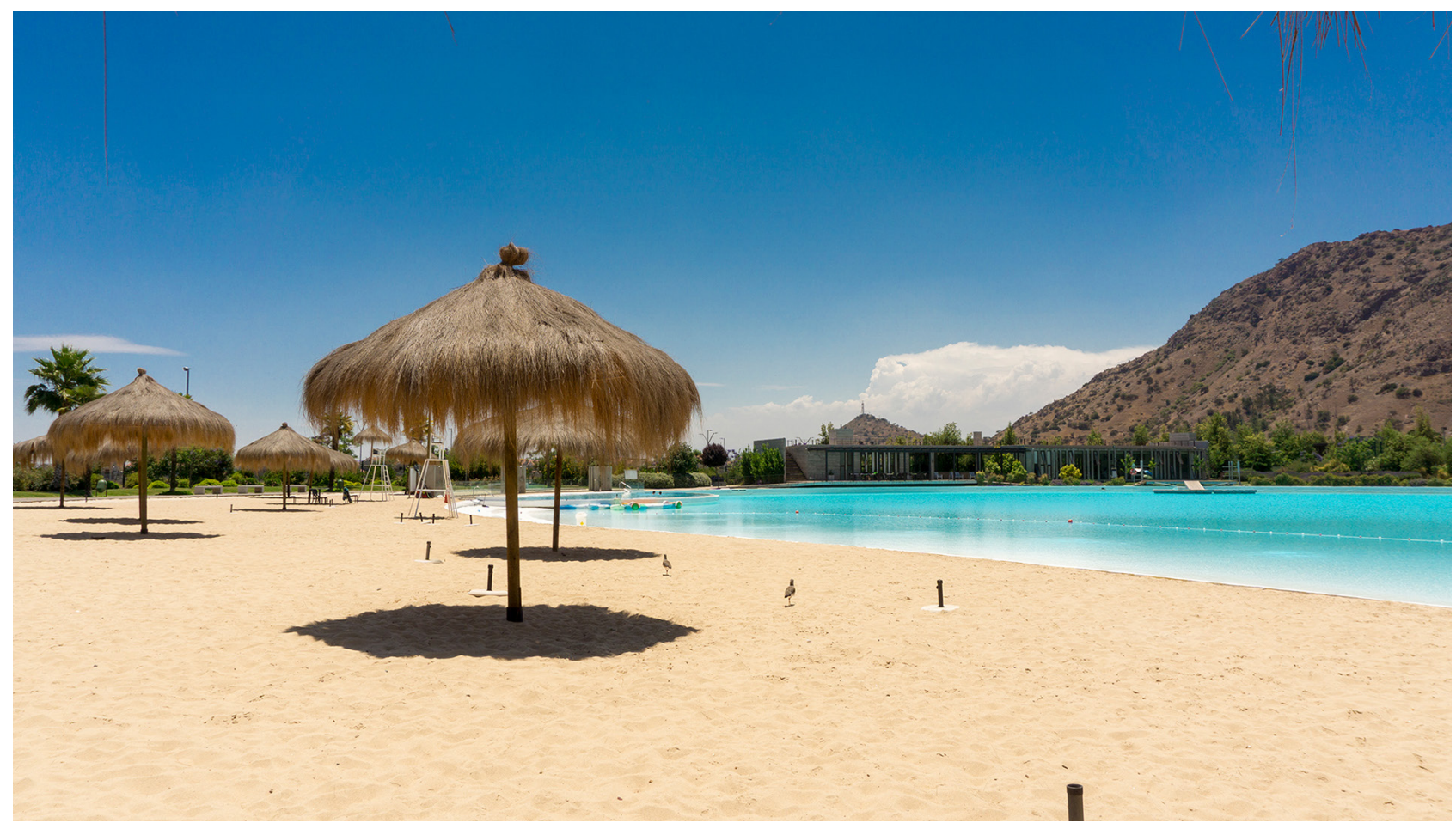

FIGURA 4. Proyecto Laguna Cóndores en San Bernardo

FUENTE: Inmobiliaria SOCOVESA (2020).

En el primer caso, se distinguen cuatro niveles según el tamaño. Un primer nivel, que puede ser denominado microurbanización cerrada (Pfannenstein et al., 2017), reconocido de esa manera en la literatura debido a su tamaño reducido. En el área de estudio, a partir de los permisos de edificación fue posible establecer la presencia de pequeñas urbanizaciones que no sobrepasan las 40 unidades. Su morfología corresponde a una construcción con base en una pequeña calle desde la cual se orientan viviendas en ambos sentidos que poseen un portón de acceso único. Este primer nivel, como muestra la Figura 4, no posee una gran superficie ni demasiada infraestructura asociada y utiliza el espacio disponible en medio de sectores de vivienda ya consolidados.

El segundo nivel ocupa una cantidad de viviendas hasta las 100 unidades. En estos casos, puede asociarse a un proyecto que en sí mismo no presenta una cantidad grande de unidades, como el caso presentado en la Figura 4. También se asocian a proyectos más grandes en construcción por etapas. Algunos ejemplos se ubican en Hacienda el Peñón en Puente alto, Condominio Caupolicán en Peñaflor o Casa Quinta en Maipú.

El tercer nivel está por encima de las 100 viviendas. En este caso, más que en el anterior, se encuentran asociados a proyectos más grandes que se construyen por etapas. Así, los permisos son autorizados por un sector específico de la urbanización, de morfología cerrada tipo condominio. En algunos casos, se encuentran asociadas a las ciudades valladas como parte de grandes urbanizaciones cerradas. Otro elemento diferenciador con el caso anterior es que prolifera una mayor cantidad de espacios comunes internos como plazas y áreas verdes, como se presenta en la Figura 5.

En el cuarto nivel, por sobre las 500 viviendas, es visible una extensión en términos de superficie: son las denominadas "ciudades valladas" (Hidalgo, 2004). En ocasiones, no se encuentra un acceso principal controlado, ya que se ubican en avenidas principales, por lo que existen espacios abiertos y cerrados en forma de condominios. A partir de la observación de 
imágenes satelitales, también se encuentran áreas verdes o corredores centrales que son de uso público.

La proliferación de estos distintos niveles está en directa relación con su ubicación y con la superficie disponible para construir urbanizaciones, ya que la ciudad presenta escasez de suelo y las comunas estudiadas, al encontrarse en las afueras del área urbana consolidada o fuera de esta, permiten su aparición. En el caso del primer nivel, aprovechan servicios existentes en áreas residenciales consolidadas, generalmente cercanas a los centros administrativos y comerciales de las comunas; de allí su morfología. A medida que aumenta la cantidad de viviendas existe una tendencia a ubicarse en las zonas periféricas de las comunas del área de estudio. En el caso de las ciudades valladas, debido a su tamaño, se ubican en donde existe uso de suelo agrícola, proyectando la mancha urbana hacia nuevos límites. Obviamente dicha situación es auspiciada desde una planificación urbana local que permite cambiar el uso del suelo.

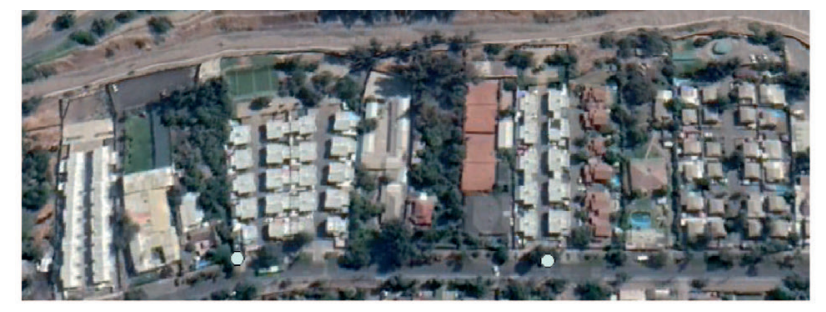

a) Viviendas de menos de 40 unidades, Comuna de la Florida

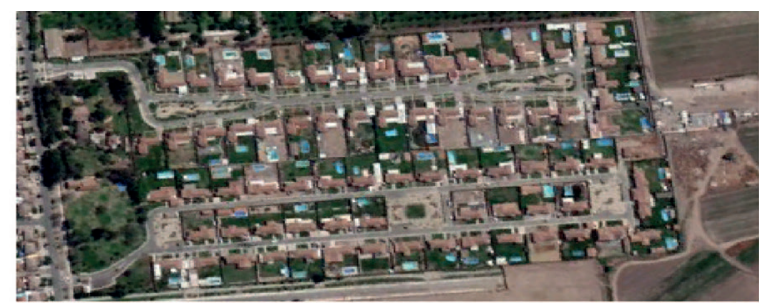

b) Urbanización de 44 unidades de lujo, comuna de Maipú

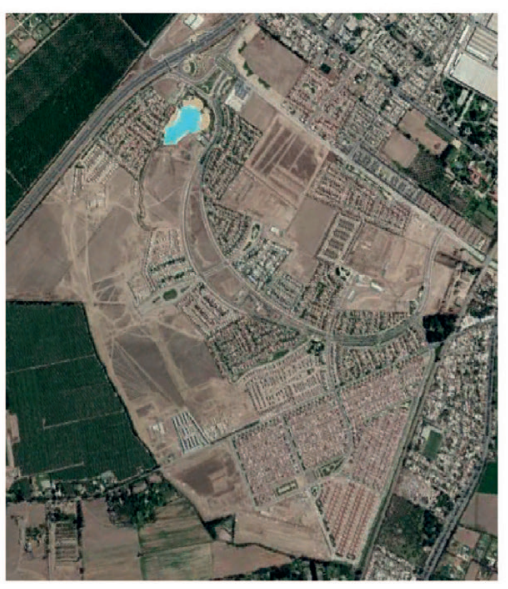

c) Laguna del Sol, urbanización cerrada por etapas, comuna de Padre Hurtado.

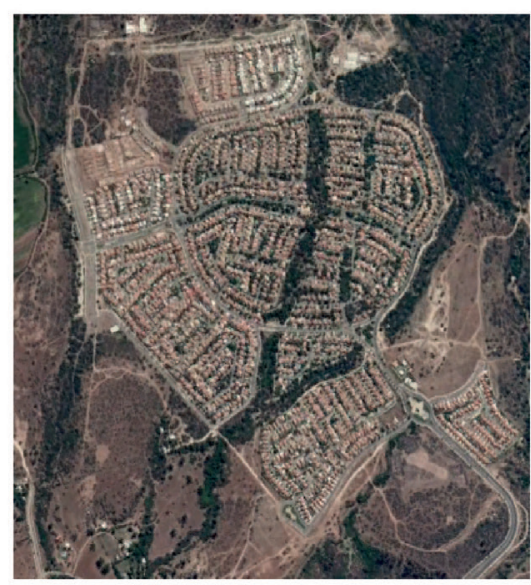

d) Urbanizaciones cerradas proyecto Hacienda Los Conquistadores, Puente Alto

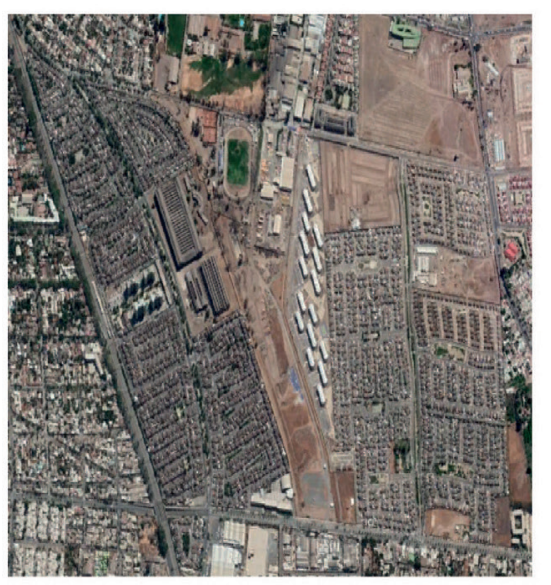

f) Ejemplos de ciudades valladas, comuna de San bernardo

FIGURA 5. Ejemplos de urbanizaciones cerradas según tamaño

FUENTE: elaboración propia con base en Permisos de Edificación INE (2020) y Google Earth (2019).

Por otra parte, según la orientación social y el precio de la vivienda, las tipologías levantas se presentan en la Tabla 1. Como Roitman (2016) manifiesta, pese a que existe una proliferación transversal de la urbanización cerrada como modelo en términos socioeconómicos, existen elementos claros que permiten establecer una polarización entre los lujos de los proyectos de elite y los que se encuentran orientados a sectores vulnerables.
Dentro de la bibliografia consultada (Borsdorf, 2002; Hidalgo, 2005; Pfannenstein et al., 2017), se plantea la existencia de diversos tipos de urbanizaciones cerradas. Existe una primera urbanización, llamada lifestyle, de elite o de lujo, cuyas características fundamentales son: alto precio, gran equipamiento interno, calidad superior de vivienda y mecanismos más desarrollados de exclusión. 
Desde esa primera aproximación, a veces se considera una tipología intermedia que incluiría sectores medios-altos emergentes que buscan diferenciarse del resto de la población con el acceso a cierto nivel de exclusividad y servicios que las urbanizaciones cerradas otorgan. Generalmente, corresponden a familias cuyas cabezas de hogar poseen estudios universitarios, de acuerdo con Borsdorf (2002). Respecto al área de estudio, esta tipología fue adoptada debido a la existencia de viviendas con un precio mayor al de las categorías más bajas, pero que poseían diferencias de infraestructura y exclusividad con respecto a las de lujo. Al mismo tiempo, poseen espacios públicos asociados a las principales avenidas que las atraviesan, áreas que son de libre uso, sin seguridad ni vigilancia.
Posteriormente, se encuentran las viviendas orientadas a sectores medios y bajos. Su característica fundamental es la ayuda por parte del Estado para obtenerlas. En el caso de estudio, dialogan con la posibilidad de obtención de subsidios, los cuales pueden ser complementados con crédito. Aquí la diferenciación se manifiesta en el tamaño de las viviendas, la superficie de los espacios comunes y la calidad de los servicios asociados. Como bien menciona Roitman (2016), las viviendas para clases bajas tienden a imitar la morfología de las de lujo, o, mejor dicho, a considerar la seguridad y el ingreso controlado como beneficios, aunque están lejos de obtener la misma calidad de vida que en otros tipos de urbanizaciones cerradas.

\begin{tabular}{|c|c|c|c|}
\hline Tipología & $\begin{array}{c}\text { Características elementales } \\
\text { y atributos }\end{array}$ & Manifestación en el área de estudio & $\begin{array}{c}\text { Ejemplos en comunas } \\
\text { estudiadas }\end{array}$ \\
\hline $\begin{array}{l}\text { Vivienda } \\
\text { de lujo }\end{array}$ & $\begin{array}{l}\text { Orientada a los sectores de } \\
\text { mayores ingresos. Exclusividad } \\
\text { y exclusión. Poseen densidad } \\
\text { baja o media. Elementos de } \\
\text { lujo. }\end{array}$ & $\begin{array}{l}\text { Son las que tienen los precios más altos, } \\
\text { que sobrepasan las } 4.000 \text { UF. Se diferencian } \\
\text { del resto por el tamaño de las propiedades } \\
\text { y viviendas, en conjunto con la infraestruc- } \\
\text { tura asociada. Siempre poseen controles } \\
\text { internos de acceso y vigilancia privada. En } \\
\text { el caso de los de mayor tamaño y enverga- } \\
\text { dura, se dividen en distintos condominios. }\end{array}$ & $\begin{array}{l}\text { Condominio Entre Cerros (Talagan- } \\
\text { te); Casaquinta (Maipú); Bisas de } \\
\text { Chena (Maipú); Hacienda Lonquén } \\
\text { (Maipú); } \\
\text { Condominio Las Nalcas (La Flori- } \\
\text { da); } \\
\text { Laguna del Sol (Padre Hurtado). }\end{array}$ \\
\hline $\begin{array}{l}\text { Vivienda } \\
\text { de clase } \\
\text { media y } \\
\text { alta }\end{array}$ & $\begin{array}{l}\text { Funcionan como proyectos } \\
\text { para incrementar el estatus so- } \\
\text { cial, diferenciándose de otros } \\
\text { sectores. Poseen vigilancia pri- } \\
\text { vada e ingresos controlados. La } \\
\text { calidad de servicios e infraes- } \\
\text { tructura es menor que en el } \\
\text { caso anterior. }\end{array}$ & $\begin{array}{l}\text { Poseen características similares al caso de } \\
\text { las primeras, aunque los elementos de lujo } \\
\text { como piscinas interiores, parques de gran } \\
\text { extensión o lagunas artificiales no se en- } \\
\text { cuentran. Su diferencia fundamental tiende } \\
\text { a ser el precio. }\end{array}$ & $\begin{array}{l}\text { Condominio Caupolican (Peñaflor); } \\
\text { Condominio Newén (Puente Alto); } \\
\text { Jardines de Peñaflor; } \\
\text { Condominio Los Nogales (Padre } \\
\text { Hurtado); } \\
\text { Condominio Los Naranjos (Maipú); } \\
\text { Icalma Barcelona (La Florida). }\end{array}$ \\
\hline $\begin{array}{c}\text { Vivienda } \\
\text { de clase } \\
\text { media }\end{array}$ & $\begin{array}{l}\text { Precio moderado de vivienda, } \\
\text { satisfacen la demanda de pri- } \\
\text { vacidad y seguridad. Poseen } \\
\text { infraestructura interna. Los } \\
\text { tamaños de la vivienda son es- } \\
\text { tandarizados, igual que su ar- } \\
\text { quitectura. }\end{array}$ & $\begin{array}{l}\text { Su principal elemento clasificador es la de- } \\
\text { limitación del precio establecida por el sub- } \\
\text { sidio a la vivienda para sectores medios DS1. } \\
\text { La calidad de sus servicios e infraestructura } \\
\text { es menor a los anteriores. }\end{array}$ & $\begin{array}{l}\text { Condominio Vistas del Maipo } \\
\text { (Puente Alto); } \\
\text { Condominio Los Cipreses (San Ber- } \\
\text { nardo); } \\
\text { Condominio Estancia Santa Cruz } \\
\text { (Padre Hurtado); } \\
\text { Condominio Borde Río (Talagante). }\end{array}$ \\
\hline
\end{tabular}




\begin{tabular}{|c|c|c|c|}
\hline Tipología & $\begin{array}{c}\text { Características elementales } \\
\text { y atributos }\end{array}$ & Manifestación en el área de estudio & $\begin{array}{c}\text { Ejemplos en comunas } \\
\text { estudiadas }\end{array}$ \\
\hline $\begin{array}{l}\text { Vivienda } \\
\text { de interés } \\
\text { social }\end{array}$ & $\begin{array}{l}\text { Orientadas a sectores más } \\
\text { vulnerables. Son parte de la } \\
\text { construcción de una ciudad } \\
\text { cerrada ya que la seguridad es } \\
\text { un atributo fundamental en la } \\
\text { búsqueda de vivienda. Pueden } \\
\text { poseer infraestructura y áreas } \\
\text { verdes, aunque siempre de me- } \\
\text { nor tamaño que en las anterio- } \\
\text { res. }\end{array}$ & $\begin{array}{l}\text { Corresponde al nivel más básico de vivienda } \\
\text { cerrada. Se asocia al subsidio de integración } \\
\text { social DS19. Presentan accesos únicos, con- } \\
\text { serjería y espacios comunes. Sus áreas ver- } \\
\text { des son de tamaño pequeño. En ocasiones } \\
\text { son colindantes con proyectos de mayores } \\
\text { recursos. }\end{array}$ & $\begin{array}{l}\text { Parque San Bernardo; } \\
\text { Parque Miguel Ángel (Puente Alto); } \\
\text { Condominio Barrio Nuevo (Puente } \\
\text { alto); } \\
\text { Condominio Solé (Padre Hurtado); } \\
\text { Parque Pablo Burchard (Padre } \\
\text { Hurtado); } \\
\text { Parque Aconcagua II (Padre Hur- } \\
\text { tado). }\end{array}$ \\
\hline $\begin{array}{l}\text { Edificios } \\
\text { de depar- } \\
\text { tamentos }\end{array}$ & $\begin{array}{l}\text { Relacionados con la ley de co- } \\
\text { propiedad, presentan acceso } \\
\text { controlado, portería y vigilancia. }\end{array}$ & $\begin{array}{l}\text { Su presencia en el área de estudio se rela- } \\
\text { ciona con el cambio en el uso de suelo ur- } \\
\text { bano que permite construcciones con más } \\
\text { pisos. Tienden a concentrarse en el centro } \\
\text { de comunas como Maipú o San Bernardo. } \\
\text { En el caso de La Florida, están asociados } \\
\text { principalmente a líneas de metro y zonas } \\
\text { de renovación urbana. }\end{array}$ & --- \\
\hline
\end{tabular}

FUENTE: elaboración propia a partir de Borsdorf (2002), Hidalgo (2004) y Pfannenstein et al. (2017).

En torno a los edificios de departamentos, su presentación en el área de estudio es variada. Por una parte, pueden existir como bloques únicos que llegan a rondar los 20 pisos. Por otra, pueden llegar a ser dos o tres torres de similares características. A medida que aumenta la cantidad de bloques, los pisos son menos y llegan a ser cercanos a los 4 o 5 pisos.

Las torres más altas son las que presentan mayor variabilidad interna, ya que poseen departamentos de diversos tamaños, en ocasiones desde un dormitorio hasta llegar a tres o cuatro. En el caso de los proyectos de cinco o seis bloques, presentan, en términos generales, un par de modelos de departamentos que no poseen tanta diferencia en cuanto a superficie.

\section{Análisis y discusión}

Dentro de las principales consecuencias que presenta la proliferación de la ciudad amurallada se encuentra la fragmentación del espacio (Janoshka \& Glasze, 2003; Roitam; 2006; Cabrales, 2006). El espacio urbano se construye a partir de discontinuidades dadas por murallas, perímetros cerrados y controles de acceso. Dicha situación no está lejos de la realidad encontrada en el área de estudio, ya que, según los permisos de edificación, el 70\% corresponde a urbanizaciones cerradas.

Por lo tanto, se comprueba que la tendencia a la pérdida de espacios públicos y el cercamiento de infraestructuras son parte tónica del área de estudio. Estas comunas comparten el patrón de construcción. Desde la exclusión y la exclusividad (Hidalgo et al., 2007; Roitman, 2003), también se presentan proyectos de lujo en donde están presentes grandes extensiones de áreas verdes, viviendas con mayor superficie y equipamiento o lagunas artificiales.

Por otra parte, en algunos casos se presentan beneficios para zonas residenciales aledañas, aunque esto no es generalizado. Estudios de otras ciudades confirman dicha tendencia (Contreras et al., 2018; Pfannenstein et al., 2017). En este estudio se constató la existencia de corredores centrales que funcionan a modo de área verde accesible para todo el mundo, de manera que se insertan alrededor de zonas residenciales en donde no existen tantas zonas de esparcimiento con atributos similares. La problemática de esta situación es que aquellos espacios realmente conlleven una coexistencia entre grupos sociales diversos, ya que de todas formas existen espacios interiores cerrados, por lo que prima la inseguridad y se mantiene la falta de 
una vida común. Al mismo tiempo, si los proyectos se ubican en las zonas más alejadas de cada comuna, pese a que existen dichos espacios no serían accesibles para todo el mundo al ubicarse distantes de las zonas residenciales de mayor data.

En torno a una explicación sobre cómo se produce la espacialidad encontrada en el área de estudio, existen elementos generales y estructurales que se articulan y dan cuenta de sus implicancias, como revisaremos a continuación. El neoliberalismo como política urbana provocó una mayor impronta de los agentes inmobiliarios en la definición de los parámetros y los tipos de proyectos. La posibilidad de generar ganancias mediante la imposición de un ideal de vivienda segura tampoco puede ser dejado de lado, ya que se presenta transversalmente en los grupos sociales.

Por otra parte, no hay que dejar de lado el papel de las políticas locales, que actúan hacia dos direcciones. En una primera aproximación, tenemos la conformación de polos de desarrollo vertical, cuya expresión más acelerada se encuentra en la comuna de La Florida, auspiciada también por su alta conectividad y por la presencia de centros comerciales. Una segunda dimensión se presenta en torno a cambios de usos de suelo y zonificaciones hacia la superficie aún no urbanizada completamente. Así, cambios en el tamaño de las propiedades y la densidad de vivienda permiten crear núcleos de elite que en ocasiones colindan con proyectos de menor nivel social. De otra parte, Puente Alto, San Bernardo, La Florida y Maipú fueron las principales comunas receptoras de viviendas sociales desde la década de los ochenta hasta principios de los 2000.

Los resultados presentados también se caracterizan desde una proliferación del encierro como modo de vida. Edward Soja (2008) establece la idea de las nuevas ciudades en donde la seguridad, la policía y las murallas conforman un nuevo entramado complejo y quebrado. El área de estudio se configura a partir de pequeñas islas y parcelaciones de urbanizaciones cerradas, las cuales se articulan a grandes avenidas. En caso de las de mayor tamaño y precio, poseen servicios internos como centros comerciales, establecimientos educacionales, centros de esparcimiento y gimnasios, entre otros, que les dan una autonomía relativa.

En conjunto con lo anterior, existe una imitación de la seguridad de dichos proyectos de elite, pese a no tener acceso a la misma calidad de vida (Roitman, 2016). Esto significa que siguen existiendo profundas desigualdades: pese a que para cualquier familia puede ser fundamental el tener un entorno apropiado para vivir y la separación de un adentro y un afuera es algo beneficioso, la variedad de proyectos encontrados clarifica que existen diferencias en cuanto al equipamiento y la infraestructura asociada.

Si la seguridad es una constante, la mayor presencia de proyectos de altos precios también lo es. Los resultados demuestran que gran parte de las urbanizaciones cerradas son concebidas para clases medias altas y altas y que no existe posibilidad de más proyectos subsidiables pese a la existencia de zonas residenciales de grupos medios y bajos en las comunas estudiadas, a la vez que superficie disponible. La ciudad crece, pero con una primacía de los sectores medios altos y altos.

Llegados a este punto, se puede plantear la pregunta sobre si las urbanizaciones cerradas son un problema en sí mismas. La respuesta general es que lo problemático son sus efectos, ya sea por la fragmentación del espacio y porque funcionan a modo de provocación de la segregación residencial. Pueden provocar una coexistencia, pero aquella existe sin posibilidad de un punto de encuentro, de construir una ciudad en común. El encierro y la seguridad siguen siendo los imperativos en la búsqueda de una vivienda (Díaz \& Ortiz, 2014).

\section{Conclusiones}

El panorama de la urbanización cerrada es complejo y presenta serios problemas para su abordaje. Por un lado, configura la construcción de la ciudad latinoamericana, pero, por otra parte, sus efectos tienden a 
ser diversos, en una mixtura de características locales con la idea de una ciudad amurallada, que también depende de los barrios y los sectores donde proliferen. En el caso de las urbanizaciones cerradas de menor tamaño, su impacto tenderá a ser menor que con la presencia de grandes condominios por sobre las cien o doscientas viviendas.

En la actualidad, se presenta la discusión sobre si la ciudad latinoamericana es menos segregada (Sabatini et al., 2017), al menos en su dimensión macro, al existir sectores de altos ingresos más disgregados en diferentes zonas, lo que no necesariamente puede ser asimilado como una integración. Por una parte, la segregación presenta cierta disminución, pero la ciudad se encuentra más fragmentada porque persiste la tendencia a la desaparición del espacio público por cuenta de la búsqueda y la promoción de una vida privada. Las avenidas principales beneficiadas con las urbanizaciones cerradas pueden permitir una mejor conectividad, pero unen islas cerradas.

Los problemas de la policía y la seguridad son temáticas claramente necesarias para abordar por parte de los Gobiernos locales. Los índices de criminalidad y victimización son consecuencia de una sociedad desigual, en donde la sobrevivencia de ciertos grupos solo es posible mediante conductas que provienen de las normas sociales. Murallas más altas, cercos eléctricos y vigilancia privada parecen no ser la solución de fondo a dicha problemática.

La espacialidad encontrada en el área de estudio se conforma a partir de fenómenos propios de toda la región que dialogan y se vinculan con las oportunidades que los territorios les entregan. Los Gobiernos locales poseen una gran responsabilidad en la existencia de urbanizaciones cerradas y la labor de los promotores inmobiliarios. A la vez, frente a la escasez de suelo, las comunas periféricas o fuera del anillo urbano consolidado se vuelven receptoras de las nuevas ofertas de vivienda, aunque, como se encontró en la muestra de proyectos inmobiliarios, una cantidad pequeña de estos son subsidiables tanto para sectores bajos como medios, lo cual puede conectarse, en futuras investigaciones, con el déficit habitacional.

\section{Referencias}

Arizaga, C. (2003). Nuevas urbanizaciones cerradas en los noventa: representaciones del suburbio en sectores medios. Instituto de Investigaciones Gino Germani, Facultad de Ciencias Sociales, Universidad de Buenos Aires.

Borsdorf, A. (2002). Barrios cerrados en Santiago de Chile, Quito y Lima: tendencias de la segregación socio-espacial en capitales andinas. En: L. F. Cabrales (coord.), Latinoamérica: paises abiertos, ciudades cerradas (pp. 581-610). Universidad de Guadalajara; Unesco.

Cabrales, L. (2006). Tendencias recientes de las urbanizaciones cerradas y polarización residencial en Guadalajara. Texto redactado con ocasión del curso "Segregación social del espacio. Nuevos enfoques y patrones emergentes en México y Chile", dictado del 11 al 14 de septiembre. PUEC-UNAM. https://cafedelasciudades.com.ar/carajillo/4_art3.htm\#mexico

Cabrales, L. \& Canosa, E. (2001). Segregación residencial y fragmentación urbana: los fraccionamientos cerrados en Guadalajara. Espiral. Estudios sobre Estado y Sociedad, 7(20), 223-253.

Calleja, L. (2018). Gated communities. Adaptación del modelo al entorno de Madrid. Universidad Politécnica de Madrid.

Carballo, T. (2002). Buenos Aires y urbanización cerrada: nuevas formas de apropiación y fragmentación del espacio urbano. En: L. F. Cabrales (coord.), Latinoamérica: países abiertos, ciudades cerradas (pp. 237-260). Universidad de Guadalajara; Unesco.

Contreras, Y., Castillo, O., \& Sánchez, A. (2018). Manifestaciones de fragmentación urbana vinculadas a urbanizaciones cerradas: el caso del Municipio Metropolitano de Zinacantepec, Estado de México, 1990-2012. Revista de Urbanismo, 39, 1-15. https:// revistaurbanismo.uchile.cl/index.php/RU/article/ view/51288

De Lima, J. \& Ribeiro, B. (2006). Os condominios horizontais fechados em ciudades médias brasileiras. En: L. F. Cabrales (coord.), Latinoamérica: países abiertos, ciudades cerradas (pp. 373-396). Universidad de Guadalajara; Unesco.

De Mattos, C. (2002). Transformación de las ciudades latinoamericanas. ¿Impactos de la globalización? EURE 
(Santiago), 28(85), 5-10. https://dx.doi.org/10.4067/ S0250-71612002008500001

Díaz, V. \& Ortiz, A. (2014). La ciudad y la arquitectura del miedo. Estudio conceptual comparativo entre el fraccionamiento habitacional cerrado de lujo contemporáneo y la bastida medieval. Revista Nodo, 16(8), 25-41.

Enríquez, J. (2007). Socialización y tipología de las urbanizaciones cerradas en Tijuana. Revista Frontera Norte, 38(19), 127-156.

Gómez, L. (2011). La segunda residencia: espacios fragmentados e interconectados. Perspectiva Geográfica, 1(15), 113-124. https://doi.org/10.19053/01233769.1734

Heynen, N. (2006). Green urban political ecologies: toward a better understanding of inner-city environmental change. Environmente and Planning A, 38(3), 499-516.

Hidalgo, R. (2004). De los pequeños condominios a la ciudad vallada: las urbanizaciones cerradas y la nueva geografia social en Santiago de Chile. EURE (Santiago), 30(91), 29-52.

Hidalgo, R. (2005). La vivienda social en Chile y la construcción del espacio urbano en el Santiago del siglo XX. Instituto de Geografía, P. Universidad de Chile; Centro de Investigaciones Diego Barrios Arana.

Hidalgo, R. Borsdorf, A., \& Sánchez, R. (2007). Hacia un nuevo tejido urbano. Los megaproyectos de ciudades valladas en la periferia de Santiago de Chile. Ciudad y Territorio. Estudios Territoriales, 34(151), 115-135. https://www.uibk.ac.at/geographie/personal/borsdorf/pdfs/cytet_151_115-sonderdruck.pdf

IConstruye (2020). Toctoc. https://www.toctoc.com/

Inmobiliaria socovesa (2020). Proyecto Laguna Cóndores. https://www.socovesa.cl/nuestros-proyectos/laguna-condores/

Instituto Nacional de Estadísticas (1992). Censo de Población y Vivienda. https://www.ine.cl/

Instituto Nacional de Estadísticas (2002). Censo de Población y Vivienda. https://www.ine.cl/

Instituto Nacional de Estadísticas (2017). Censo de Población y Vivienda. https://www.ine.cl/

Instituto Nacional de Estadísticas (2020). Permisos de Edificación. https://www.ine.cl/estadisticas/economia/ edificacion-y-construccion/permisos-de-edificacion

Janoschka, M. (2002). El nuevo modelo de la ciudad latinoamericana: fragmentación y privatización. EURE (Santiago), 28(85), 11-20. http://www.eure.cl/index. $\mathrm{php/eure/article/view/1239}$
Janoschka, M. \& Glazse, G. (2003). Urbanizaciones cerradas: un modelo analítico. Ciudades, 59, 9-20.

López-Morales, E., Gasic, I., \& Meza, D. (2012). Urbanismo pro-empresarial en Chile: políticas y planificación de la producción residencial en altura en el pericentro del Gran Santiago. Revista INVI, 27(76), 75-114. https:// dx.doi.org/10.4067/S07 18-83582012000300003

Montañez, L. (1999). Espacio - espacialidad y transdisciplinariedad en geografía. Cuadernos de Geografia, 8(1), 59-73. https://revistas.unal.edu.co/index.php/rcg/ article/view/71607

Pfannenstein, B., Anacleto, E., \& Sevilla, S. (2017). La ciudad cerrada y su diversificación como reto del Área Metropolitana de Guadalajara, México. Revista de Geografia Norte Grande, 68, 163-184. https://dx.doi. org/10.4067/S07 18-34022017000300163

Roitman, S. (2003). Barrios cerrados y segregación social urbana, Scripta Nova, 8(146). http://www.ub.edu/geo$\mathrm{crit} / \mathrm{sn} / \mathrm{sn}-146(118) \cdot \mathrm{htm}$

Roitman, S. (2004). Urbanizaciones cerradas: estado de la cuestión hoy y propuesta teórica. Revista de Geografia Norte Grande, 32, 5-19.

Roitman, S. (2016). Urbanizaciones cerradas a escala planetaria. Prospectiva. Revista de Trabajo Social e Intervención Social, 21, 13-22.

Sabatini, F., Cáceres, G., \& Cerda, J. (2001). Segregación residencial en las principales ciudades chilenas: tendencias de las tres últimas décadas y posibles cursos de acción. EURE (Santiago), 27(82), 21-42. http://www. eure.cl/index.php/eure/article/view/1258

Sabatini, F., Rasse, A., Cáceres, G., Robles, M., \& Trebilcock, M. (2017). Promotores inmobiliarios, gentrificación y segregación residencial en Santiago de Chile. Revista Mexicana de Sociología, 79(2), 229-260. http:// www.scielo.org.mx/scielo.php?script=sci_arttext\&pi$\mathrm{d}=\mathrm{S} 0188-25032017000200229 \& \operatorname{lng}=\mathrm{es} \& \mathrm{nrm}=\mathrm{i}-$ so\&tlng $=\mathrm{es}$

Smith, N. (2008). Uneven development: nature, capital, and the production of space. University of Georgia.

Soja, E. (2008). Postmetrópolis. Estudios críticos sobre las ciudades y las regiones. Traficantes de Sueños.

Souza, C. (2008). A vida em separado. Estudo de um condominio fechado de Porto Alegre. [Tesis de grado]. Universidade Federal do Rio Grande do Sul. http://www.lume.ufrgs.br/bitstream/handle/10183/17524/000715370. pdf 
Tapia, R. (2011). Vivienda social en Santiago de Chile. Análisis de su comportamiento locacional, período 1980-2002. Revista INVI, 26(73), 105-131.

Thuillier, G. (2005). El impacto socio-espacial de las urbanizaciones cerradas: el caso de la Región Metropolitana de Buenos Aires. EURE (Santiago), 31(93), 5-20.
Vergara-Perucich, F. (2017). The neoliberal urban utopia of Milton Friedman: The Case of Santiago. En: C. Bonoano \& F. Vergara-Perucich (eds.), Neoliberalism and Urban Development in Latin America. The Case of Santiago (pp. 21-38). Routledge. 